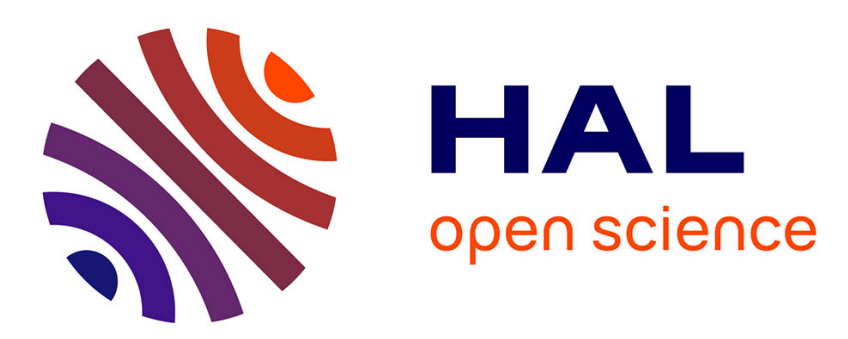

\title{
Angle Resolved NEXAFS Spectra of Hexagonal and Cubic GaN
}

\author{
M. Katsikini, E. Paloura, T. Cheng, C. Foxon
}

\section{To cite this version:}

M. Katsikini, E. Paloura, T. Cheng, C. Foxon. Angle Resolved NEXAFS Spectra of Hexagonal and Cubic GaN. Journal de Physique IV Proceedings, 1997, 7 (C2), pp.C2-1129-C2-1130. 10.1051/jp4:19972157 . jpa-00255220

\section{HAL Id: jpa-00255220 https://hal.science/jpa-00255220}

Submitted on 1 Jan 1997

HAL is a multi-disciplinary open access archive for the deposit and dissemination of scientific research documents, whether they are published or not. The documents may come from teaching and research institutions in France or abroad, or from public or private research centers.
L'archive ouverte pluridisciplinaire HAL, est destinée au dépôt et à la diffusion de documents scientifiques de niveau recherche, publiés ou non, émanant des établissements d'enseignement et de recherche français ou étrangers, des laboratoires publics ou privés. 


\title{
Angle Resolved NEXAFS Spectra of Hexagonal and Cubic GaN
}

\author{
M. Katsikini****, E.C. Paloura**, ${ }^{*}$, T.S. Cheng*** and C.T. Foxon*** \\ * Aristotle University of Thessaloniki, Department of Physics, 54006 Thessaloniki, Greece \\ ** Hahn-Meitner Institute (A.S.), Glienicker Str. 100, 14109 Berlin, Germany \\ *** University of Nottingham, Department of Physics, NG7 2RD,UK
}

\begin{abstract}
Phase stabilised cubic and hexagonal GaN thin films, grown by MBE, are studied using angle ( $($ ) resolved NEXAFS measurements at the N-K-edge. It is demonstrated that the energy positions and intensities of the characteristic NEXAFS resonances depend on the crystal symmetry and can be used as a fingerprint of the symmetry of the examined crystal. Deviations from the cubic or hexagonal symmetries are clearly detectable since they lead to a shift in the resonances of the NEXAFS structure and a characteristic intensity angular dependence. Based on the above results, a formalization for a quantitative assessment of the cubic and hexagonal contributions in a mixed crystal is discussed.
\end{abstract}

\section{Introduction}

GaN has recently attracted a lot of interest because it is a material system suitable for opto-electronic devices operating in the blue-UV[1] while high brightness blue light emitting diodes have already been demonstrated using the GaN/InGaN/AlGaN system[2]. GaN can crystallise in either the stable wurtzite $(\alpha)$ form or the metastable zinc-blende ( $\beta$ ) phase; this depends on both the type and crystal orientation of the substrate as well as on the growth conditions and often results in growth of mixedphase crystals. Here we report on the characterisation of phase-stabilised GaN grown by MBE, using the angular ( $\Theta$ ) dependence of the NEXAFS spectra recorded at the N-K-edge.

\section{Results and Discussion}

The samples were grown on (001) $\mathbf{n}^{+}-\mathrm{GaP}$ in a Varian MBE system equipped with an if activated plasma source operating at $13.56 \mathrm{MHz}$. The stabilisation of the $\alpha-$ or $\beta-\mathrm{GaN}$ phase was achieved by the control of an impinging arsenic flux on the growth surface. The $\alpha-\mathrm{GaN}$ and $\beta-\mathrm{GaN}$ (MG84 and MG108) were grown at $620^{\circ} \mathrm{C}$ and $700^{\circ} \mathrm{C}$, respectively, and the corresponding film thicknesses are $\mathrm{d}=500$ and $120 \mathrm{~nm}$. The mixed phase sample (MG89 with $\mathrm{d}=500 \mathrm{~nm}$ ) was grown at $620^{\circ} \mathrm{C}$. Prior to the NEXAFS measurements the GaN films were characterised by X-ray diffraction (XRD), Auger electron spectroscopy (AES) and high energy electron diffraction (RHEED)[3]. The NEXAFS spectra were recorded at room temperature, at the N-K-edge (390-440eV), using the SX-700-I plane grating monochromator at the electron storage ring BESSY in Berlin. Detection was in the fluorescence mode using a high purity Ge detector, and the NEXAFS spectra were recorded as a function of the angle of incidence 9 which is defined by the incident beam and the sample surface. The spectra were fitted using a step-function, to simulate the absorption edge, and a number of gaussians to fit the individual resonances. Prior to fitting the spectra were subjected to linear background subtraction and normalisation to the atomic limit.

For cubic symmetry, the allowed transitions are $1 \mathrm{a}_{1} \rightarrow \mathrm{t}^{*}{ }_{2}$, where $\mathrm{t}_{2}$ belongs to a 3-dimensional irreducible representation $\left(T_{2}\right)$ of the group $T_{d}$ and is observed with the same intensity for all angles of incidence. The allowed transitions for the $C_{6 v}$ hexagonal symmetry are $1 a_{1} \rightarrow a_{1}{ }^{*}$ and $1 a_{1} \rightarrow e^{*}{ }_{1}$ which are strongest for grazing and normal incidence, respectively[4]. In the $1 a_{1} \rightarrow a_{1}{ }^{*}$ transition the final state can result from mixing of $s$ and $p_{z}$ orbitals while in $1 a_{1}$ $\rightarrow \mathrm{e}^{*}$ the final state can result from mixing of $p_{\mathrm{x}}$ and $p_{\mathrm{y}}$ orbitals. The energy positions, $\triangle \mathrm{E}_{\mathrm{j}}$, of the individual NEXAFS resonances are measured relative to the absorption edge, which is defined as the inflection point of the step function. The areas under the resonances in the spectra from $\beta$-MG84 are, within the experimental error, independent of 3 . This result is in agreement with the theoretically expected behaviour of a cubic sample. Contrary to that, the NEXAFS spectra from the $\alpha-\mathrm{MGl} 108$ have a strong angular dependence, as shown in Fig. 1 where the areas under the resonances are plotted versus $\cos ^{2} \theta$. In the figure, the areas are normalised to the area corresponding to the "magic" angle $\vartheta=54.7^{\circ}$, i.e. the

${ }^{(1)}$ On leave from: Aristotle University of Thessaloniki, Department of Physics 54006 Thessaloniki, Greece. 
characteristic angle for a sample with $\mathrm{C}_{6 \mathrm{v}}$ hexagonal symmetry for which the NEXAFS spectra are independent of the angle between the final state vector or plane molecular orbital and the normal to the sanple surface.

The characteristic energy positions $\Delta \mathrm{E}_{\mathrm{i}}$ for the $\alpha$ - and $\beta-\mathrm{GaN}$ are listed in Table 1 (the errors due to the fitting are smaller than the $100 \mathrm{meV}$ step used for the measurements). It should be pointed out that $\Delta \mathrm{E}_{\mathrm{i}}$ and the corresponding FWHM are found to be constant for the pure cubic and hexagonal samples, for any angle of incidence.

Table 1: Energy positions of the resonances in the NEXAFS spectra for the pure cubic and hexagonal samples.

\begin{tabular}{||c|c|c|c|c|c|c|}
\hline sample & $\mathrm{E}_{1}(\mathrm{eV})$ & $\mathrm{E}_{2}(\mathrm{eV})$ & $\mathrm{E}_{3}(\mathrm{eV})$ & $\mathrm{E}_{4}(\mathrm{eV})$ & $\mathrm{E}_{5}(\mathrm{eV})$ & $\mathrm{E}_{6}(\mathrm{eV})$ \\
\hline$\beta$-MG108 & 1,94 & 4,79 & 7,23 & 8,71 & 11,39 & - \\
\hline$\alpha-\mathrm{MG} 84$ & 1,91 & 4,26 & 6,54 & 9,00 & 10,52 & 12,70 \\
\hline
\end{tabular}

As shown in the Table the energy position of all the resonances, with the exception of $G_{1}$ which appears at the same energy for all the examined crystals, depends on the crystal symmetry. If the sample is mixed, then the energy position of the resonances depends on $\vartheta$ and shifts between the limits set by the cubic and hexagonal structures. Given the constancy of the $\Delta \mathrm{E}_{\mathrm{i}}$ for pure cubic and hexagonal phases, it can be proposed that the NEXAFS spectra can be used as a fingerprint of the $\alpha$ - or $\beta$-GaN phases, while any deviation of the $\Delta E_{j}$ 's from the values corresponding to $\alpha-$ or $\beta-G a N$ indicates the coexistence of both $\alpha$ - and $\beta$ - GaN, i.e. a mixed-phase sample.

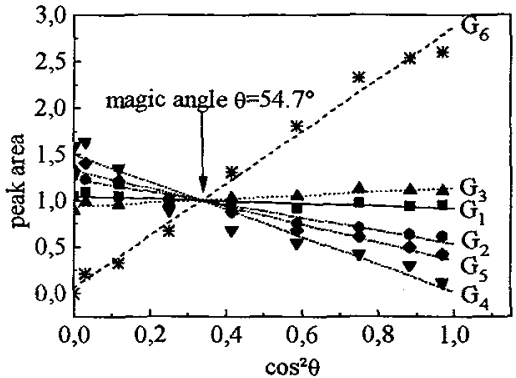

Fig. 1 : Areas under the NEXAFS resonances versus $\cos ^{2} \theta$ for MG84.

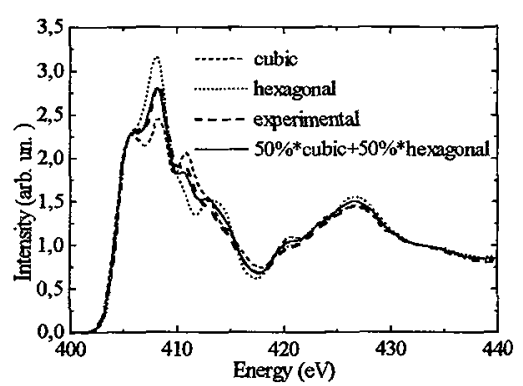

Fig. 2 : The as-recorded NEXAFS spectra from MG84, MG108 and MG89 and the simulated spectrum for MG89 $\left(9=80^{\circ}\right)$

It is proposed that the NEXAFS spectra from a mixed-phase sample can be approximated by the weighted average of the spectra from the pure cubic and hexagonal samples, where the weight factors reflect the fraction of the cubic and hexagonal phases present in the sample. Following this procedure the NEXAFS spectrum from the mixed-phase sample MG89 can be reproduced by averaging the NEXAFS spectra from the pure cubic and hexagonal samples weighted by $50 \%$ and $50 \%$, respectively. The resulting spectrum is shown in Fig. 2 (continuous line) along with the recorded spectra from the mixed (thick dashed line), the cubic (dashed line) and hexagonal (dotted line) samples. As shown in the figure, this simple model for the NEXAFS structure of the mixed crystal predicts the experimental spectrum quite accurately.

\section{Conclusions}

It is demonstrated that the NEXAFS spectra can be used as a fingerprint of the cubic or hexagonal symmetry for epitaxial GaN. The energy positions of the resonances are independent of the angle of incidence for either polytype, while their oscillator strengths (areas under the gaussians) are independent of the angle of incidence only if the sample is pure cubic. Mixing of the $\alpha$ - or $\beta-\mathrm{GaN}$ phases can be detected as an angle-dependent shift of the energy positions of the NEXAFS resonances from the values corresponding to a pure cubic or hexagonal sample. Application of the procedure to the mixed-phase sample MG89 has yielded results that are in very good agreement with the recorded spectrum.

Acknowledgements : Financial support from the EC-HCM (CHGE-CT93-0027) program is gratefully acknowledged.

[1] S. Strite and H. Morkoc, J. Vac. Sci. Technol. B10, 1237, 1992

[2] S. Nakamura, T. Mukai and M. Senoh, Appl. Phys. Lett. 64, 1687, 1994

[3] T. S. Cheng, L. C. Jenkins, S. E. Hooper, C. T. Foxon, J. W. Orton and D. E. Lacklison, Appl. Phys. Lett. 66, 1509 (1995) (and references therein).

[4] "Chemical applications of group theory" F. A. Cotton, Wiley-Interscience, New York (1971) 